\title{
He decidido proponerte una cita
}

\author{
Pedro Pablo Gómez Moreno \\ Editor \\ Universidad Distrital Francisco José de Caldas, \\ Colombia \\ ppgomezm@udistrital.edu.co
}

Cómo citar este artículo: Gómez Moreno, Pedro Pablo (2022). He decidido proponerte una cita. Estudios Artísticos: Revista de investigación creadora, 8(12). pp 14 - 16. DOI: https://doi. org/10.14483/25009311.18763

Palabras clave (2021). OJS Revista Estudios Artísticos: captura de pantalla.

\section{(c) (i)}

https://creativecommons.org/licenses/by/4.0/deed.es
En la segunda estrofa de la canción titulada: Una cita, del compositor caldense Pedro Nel Isaza, podemos escuchar la siguiente interpelación: "He decidido proponerte una cita; $y$ de una vez logremos la ocasión; pa que me digas si me amas o no me amas, o si en tu pecho se anida ya otro amor". En este caso, la cita que quiero proponer a los autores, que realizan envíos a Estudios Artísticos, tiene un sentido un poco distinto, aunque sí tiene que ver con el mundo de los afectos y de los vínculos de los que trata la canción de Isaza.

Estudios Artísticos: revista de investigación creadora, es la segunda revista de la Universidad Distrital Francisco José de Caldas, que tengo el honor de editar, desde el año 2015 a la fecha, después de haber liderado su creación e institucionalización. La primera es Calle14: revista de investigación en el campo del arte, creada en el año 2007. Esta desmesura ha significado, para mí, enormes retos personales, en cuestión de tiempos académicos, retos en la gestión, conformación de comités editoriales y de apoyo, además de la crítica de algunos colegas que ven en esta actitud una intención de abarcar demasiado. La idea de tener una revista con el mismo nombre de la denominación de un programa de estudios de maestría y otro de doctorado surge de la necesidad de proveer, a los investigadores-creadores del emergente campo de los estudios artísticos, de un medio de circulación y apropiación social, creado y agenciado por las comunidades mismas de este campo epistémico y creador emergente en el contexto de las geopolíticas del conocimiento de y desde el Sur Global.

Afortunadamente, los colegas de distintos campos disciplinares de las artes, las ciencias sociales y las humanidades han aceptado el reto de confiar 
los resultados de sus indagaciones para ser socializados en nuestras páginas. Y esa confianza ha sido fértil al punto que hoy podemos dar cuenta de algunos resultados e indicadores interesantes. Desde el año 2015 a la fecha hemos logrado indexaciones internacionales en: Directory of Open Access Journal DOAJ; Sherpa/Romeo; Latindex; LatinRev; Actualidad Iberoamericana; Redib; ErihPlus; Dialnet; WorldCat y Amelica. Esto es un indicador de la proyección internacional de la revista y de su carácter abierto a comunidades académicas amplias de América Latina, España y EI Caribe. A la vez contamos con indicadores interesantes en lo que respecta a consultas de artículos, lo que muestra la pertinencia temática del enfoque de la revista para los lectores especializados y no especializados: El artículo Visual Virtual MT: relato de una pesquisa de los autores Brandão et al., tiene a la fecha 12.811 consultas del resumen y 480 consultas del archivo. Por su parte, el artículo: Breve historia del rock en Colombia de Ortegón Munevar C., cuenta con 762 consultas de resumen y 5.118 visualizaciones del archivo. Además, con base en los datos de Publish or Perish, en el periodo 2015 2020 hemos publicado un total de 83 artículos, cuyas lecturas han generado 112 citaciones en publicaciones especializadas, con un promedio de 18,67 citaciones al año, para un índice $\mathrm{h}$ de la revista de 4 y un índice g de 8 . Claramente, estos resultados son modestos si nos comparamos con otras revistas de más amplia trayectoria, pero a la vez nos llenan de optimismo porque muestran el potencial de Estudios Artísticos y su amplio horizonte de expectativas.

Ahora bien, la cita que quiero proponerles a nuestros lectores, especialmente a los autores que están considerando realizar un envío, tiene que ver con la invitación a encontrarse con los autores de nuestra revista. Se trata de una cita para recibir sus mensajes, para leer sus artículos y establecer una conversación cálida y directa con ellos. Una conversación que puede abarcar un abanico amplio de temas y problemas inter y transdisciplinares, como se puede ver en la gráfica que abre este texto editorial. Y, por supuesto, se trata de una invitación a valorar el trabajo de nuestros autores y a considerar sus productos como fuente de referencia y citación.
En otras palabras, las revistas académicas en general y Estudios Artísticos en particular son fuentes valiosas para los investigadores de un determinado campo del conocimiento. $Y$ una visita a sus archivos, cuidadosamente ordenados e indexados, para facilitar el acceso, la lectura y la referencia, debería ser un ejercicio cada vez más frecuente de parte de los autores. El resultado no puede ser otro que la posibilidad de tejer comunidades académicas cada vez más fortalecidas, y reconocer el carácter colectivo y comunal y localizado del conocimiento. Todo esto es mucho más satisfactorio si está mediado por el reconocimiento mutuo, el respeto y la solidaridad.

Con una bienvenida a la lectura, la colección de trabajos de estos 12 números de Estudios Artísticos se abre nuevamente a la mirada atenta y a la inteligencia sintiente de nuestros lectores y lectoras.

\section{Referencias}

Gómez Moreno, P. P. (2017). La investigacióncreadora o el horizonte ampliado de la investigación-creación. Estudios Artísticos: revista de investigación creadora, 3(3), pp. 8-11. https://doi. org/10.14483/25009311.12525. 